\section{Metabolic disturbance in first-episode}

\section{schizophrenia}

JOGIN H. THAKORE

\begin{abstract}
Background Schizophrenia shortens life, e.g. through suicide and obesityrelated diseases such as type 2 diabetes mellitus. It is assumed that medications play a major role, but most of the evidence for this comes from studies poorly controlled for variables such as lifestyle and medication status.
\end{abstract}

\begin{abstract}
Aims To determine whether schizophrenia is associated (independently of medication) with the development of certain metabolic disturbances and whether these might be explained by stress axis dysfunction.
\end{abstract}

\section{Method Literature review.}

Results Most studies did not control for confounding factors such as previous usage of medication, lifestyle, age and ethnicity. A few conducted in drug-naïve patients with first-episode schizophrenia appear to indicate that these patients have higher than expected rates of visceral obesity and impaired fasting glucose concentrations, which may be related to a subtle disturbance of the hypothalamicpituitary-adrenal axis.

\section{Conclusions Schizophrenia is} independently associated with physical illnesses that have a metabolic signature. Therefore, patients need to have a thorough physical assessment at diagnosis and at regular intervals thereafter. Metabolic disturbances have been found in drugnaïve patients with first-episode illness and may be an inherent part of the illness.

Declaration of interest J.H.T. is supported by a grant from Eli Lilly \& Co. issues are described.
Schizophrenia is a life-shortening disease (Brown, 1997). Premature death is common, with life expectancy reduced by over $20 \%$. Although suicide remains the single largest cause of death at $28 \%$, the lifetime risk of suicide has been adjusted from $10 \%$ to $4 \%$ because most of the deaths occur within the first year following diagnosis (Inskip et al, 1998). Over $60 \%$ of the deaths in schizophrenia are accounted for by natural causes such as cardiovascular illness; the standardised mortality ratios for cardiovascular illness in schizophrenia are twice as high as those for the general population (Brown et al, 2000). Predisposing factors for cardiovascular illness include non-modifiable factors such as age, gender and family history, and modifiable risk factors such as lifestyle and various biochemical parameters, of which obesity is one (Goldbourt \& Neufeld, 1988; Wood et al, 1998).

\section{METHOD}

The topics of obesity, type 2 diabetes mellitus and hypothalamic-pituitary-adrenal (HPA) axis, and schizophrenia, were reviewed using an electronic database (Medline) and a manual search of papers published before 1966. In addition, studies conducted by J.H.T. pertaining to these

\section{RESULTS}

\section{Obesity and schizophrenia:} location, location, location?

Obesity is a worldwide epidemic and it is estimated that 300 million people are obese, defined as having a body mass index (BMI) in excess of $30 \mathrm{~kg} / \mathrm{m}^{2}$ (for review, see Hill et al, 2003). A meta-analysis (Allison et $a l, 1999 b$ ) and review (Taylor \& McAskill, 2000) have suggested that antipsychotic drugs - in particular, certain atypical antipsychotic agents - are associated with this weight gain, and schizophrenia has been associated with obesity (Brugha et al, 1989; Kendrick, 1996; Allison et al, 1999a). Certain illnesses such as type 2 diabetes mellitus, insulin resistance, dyslipidaemias and cardiovascular disorders, together with obesity, have been termed the metabolic syndrome (Reaven, 1988) and appear to occur more frequently in people with schizophrenia, as has been shown by a recent study conducted in Finland (Heiskanen et al, 2003). It is believed that obesity-related illnesses may be associated particularly with an increase in visceral fat, the most metabolically active constituent of abdominal obesity (Ryan $\&$ Thakore, 2002).

In order to control for the confounding effects of medication, we measured visceral fat distribution using computed tomography in 15 patients with schizophrenia and matched them with healthy controls in terms of age, exercise, diet, smoking habits and alcohol intake (Thakore et al, 2002). Seven patients were drug-naïve and the rest had not taken any oral neuroleptic preparation for at least 6 weeks and had had no intramuscular preparation for 6 months; none of the patients had been taking any form of atypical neuroleptic agent prior to entering the study. Patients with schizophrenia had a higher mean BMI than the control group: 26.7 (s.d.=1.1) kg/m $\mathrm{m}^{2} v$. 22.8 (s.d. $=0.5) \mathrm{kg} / \mathrm{m}^{2}$. Patients and controls had similar amounts of total body fat and subcutaneous fat, but the patients had over 3.4 times more intra-abdominal fat than the normal controls: 13232.0 (s.d. $=2666.5) \mathrm{mm}^{2} v .3879 .9$ (s.d. $\left.=571.9\right) \mathrm{mm}^{2}$ However, there was no difference in intraabdominal fat distribution between patients who were drug-naïve and those who were drug-free: 12442.4 (s.d. $=9762.6) \mathrm{mm}^{2} v$. 14133.9 (s.d. $=11656.8) \mathrm{mm}^{2}$.

An increase in visceral fat is not merely a 'mass effect' of a raised BMI; Enzi et al (1986) found that healthy volunteers with BMI values $\geqslant 26$ had less intraabdominal fat $\left(4650 \mathrm{~mm}^{2}\right)$ than the patients in our study $\left(13232 \mathrm{~mm}^{2}\right)$. Chronically elevated levels of cortisol, also seen in our study, may provide an explanation for the increase in intra-abdominal fat, as the density of glucocorticoid receptors (cytosolic signal transducers for steroids such as cortisol) and the concentrations of the lipogenic enzyme lipoprotein lipase (a key enzyme in fat deposition) are higher in visceral fat than in subcutaneous fat (Ottoson et al, 1994; Pedersen et al, 1994). 


\section{Hyperglycaemia, insulin resistance and schizophrenia: an illness effect?}

Even though the higher rates of type 2 diabetes mellitus observed in people with schizophrenia have been attributed to the use of antipsychotic medications - in particular, atypical agents - this is by no means a universally accepted finding. For instance, Mukherjee et al (1996) studied a cohort of patients with schizophrenia $(n=95)$, and observed that the prevalence of diabetes was age-dependent and greater in those taking conventional neuroleptic medications. Subramaniam et al (2003) reported a rate of undiagnosed diabetes mellitus of $16 \%$ and a rate of impaired glucose tolerance of just over $30 \%$ in a cohort of residential patients with schizophrenia, none of whom had ever received an atypical neuroleptic drug; yet the rate of type 2 diabetes mellitus in the general population of a similar age was over $22 \%$, indicating that patients with schizophrenia are less likely to have their diabetes diagnosed than their counterparts without mental illness.

The introduction of atypical neuroleptics has added to this debate, although most of the evidence implicating these compounds is based on case reports and various cross-sectional epidemiological studies (Liebzeit et al, 2001; Sernyak et al, 2002). In contrast to these findings, Lieberman et al (2003) conducted a prospective study in a Chinese population, comparing chlorpromazine with clozapine in drug-naïve patients with first-episode schizophrenia over a 52-week period, and showed that despite significant increases in weight (which were equal between the two compounds in question), there was no significant increase in fasting plasma glucose levels at the end of the study period. However, the study did not have a normal control group as a reference population. This is important, because the rates of obesity and type 2 diabetes mellitus in this population are lower than those found in North America, or indeed in Europe. Furthermore, lifestyle issues such as diet and exercise were not discussed either before or during the treatment period.

Is it possible that a mechanism other than medication might be responsible for such findings? A number of papers from the era before the use of antipsychotic drugs add credence to this hypothesis, although problems with diagnosis, small size of study group and other methodological issues make it difficult to interpret the significance of these valuable earlier studies (Lorenz, 1922; Braceland et al, 1945; Freeman, 1946; Langfeldt, 1952). It is notable that a family study found that up to $19 \%$ of first-degree relatives of patients with schizophrenia had type 2 diabetes mellitus, which indicates that this endocrine condition and schizophrenia might have a genetic association (Mukherjee et al, 1989).

In an attempt to determine whether schizophrenia is associated with abnormal glucose metabolism, we compared fasting levels of plasma glucose, insulin, lipids and cortisol measures in a group of hospitalised, drug-naïve patients with first-episode schizophrenia $(n=26)$ with those of a healthy volunteer group matched in terms of age, ethnicity, exercise, diet, smoking habits and alcohol intake (Ryan et al, 2003). Anthropometric and lifestyle data indicated that the only significant difference between the two groups was that patients had a higher saturated fat intake than did controls. Over $15 \%$ of patients with schizophrenia had impaired fasting glucose levels - compared with none in the control group - as defined by the American Diabetes Association (1997) criteria. Patients with schizophrenia, compared with the control group, had significantly higher plasma levels of fasting glucose $\quad(5.3 \quad($ s.d. $=0.9) \mathrm{mmol} / \mathrm{l} \quad v . \quad 4.8$ (s.d.=0.3) mmo/l), insulin $(68.2 \quad$ (s.d.= 64.6) $\mathrm{pmol} / \mathrm{l} \quad v .55 .2 \quad(\mathrm{~s} . \mathrm{d} .=26.5) \mathrm{pmol} / \mathrm{l})$ and cortisol $(499.4($ s.d. $=161.4) \mathrm{nmol} / \mathrm{l} v$. 303.2 (s.d. $=10.5) \mathrm{nmol} / \mathrm{l}$ ), and were more insulin-resistant: $2.3 \quad($ s.d.=1.0) $\quad v . \quad 1.7$ (s.d.=0.7). Both the control and the patient groups had similar levels of lipids. Finally, there was no significant association between severity of symptoms and plasma levels of glucose, indicating that the 'stress of hospitalisation' was an unlikely cause of the hyperglycaemia.

The rate of impaired fasting glucose concentration observed in our group of patients $(>15 \%)$ is greater than that found in a recent European study $(8.5 \%$, Gourdy et al, 2001). Type 2 diabetes mellitus and vascular complications occur in a third of those with impaired fasting glucose levels (Alberti, 1996). Medication, age, ethnicity, physical inactivity and smoking are unlikely to explain our findings (King \& WHO Ad Hoc Reporting Group, 1993; Shaten et al, 1993). Although our patients consumed more saturated fat, studies do not indicate a positive association between a high intake of saturated fat and hyperglycaemia (Colditz et al, 1992; Salmeron et al, 1997,
2001), however, patients with schizophrenia did have higher levels of cortisol than did normal controls.

\section{Are patients with schizophrenia biologically stressed?}

A common endocrine reaction to stress involves activation of the hypothalamicpituitary-adrenal (HPA) axis (Axelrod \& Reisine, 1984). As in Cushing's syndrome and melancholic depression (Wajchenberg et al, 1995; Condren \& Thakore, 2001; Thakore et al, 2002), a dysregulated HPA axis can lead to abnormal glucose metabolism and visceral obesity (Rosmond \& Bjorntorp, 2002). Schizophrenia is associated with abnormalities of this axis (Altamura et al, 1989; Coryell \& Tsuang, 1992; Kaneko et al, 1992; Lammers et al, 1995), and we have confirmed this using a rather crude indicator of HPA axis activity in two studies (Thakore et al, 2002; Ryan et al, 2003).

To date, HPA axis disturbance has been less consistently reported in schizophrenia than in depression (Holsboer, 1998; Cotter $\&$ Pariante, 2002). With respect to schizophrenia, adrenocorticotrophic hormone (ACTH) and cortisol responses to corticotrophin-releasing hormone (CRH) are indistinguishable from controls, although pre-treatment with dexamethasone results in an exaggerated CRH-induced pituitaryadrenal response in patients (Roy et al, 1986; Lammers et al, 1995). Most (but not all) studies have shown that dexamethasone suppresses plasma levels of cortisol in patients with schizophrenia (Dewan et al, 1982; Tandon et al, 1991). Equally discordant findings have been reported in terms of basal activity of the HPA axis as measured by serum cortisol levels (Gil-Ad et al, 1986; Roy et al, 1986; Whalley et al, 1989; Van Cauter et al, 1991; Breier \& Buchanan, 1992; Rao et al, 1995; Elman et al, 1998; Kaneda et al, 2002). Methodological problems may partly explain the differences observed between the studies quoted. For instance, the effects of medication on HPA axis activity are unclear (Hellewell, 1999), and often a single sample of cortisol has been used to determine HPA activity although it is not clear whether this accurately represents an estimate of mean 24 h activity (Muller $\&$ von Werder, 1989).

As mean or integrated measures, such as area under the curve (AUC), of plasma cortisol between $13.00 \mathrm{~h}$ and $16.00 \mathrm{~h}$ can be used to detect hypercortisolism 
(Halbreich et al, 1982), we decided to determine cortisol, ACTH and arginine vasopressin (AVP) levels in drug-naïve patients with first-episode schizophrenia and compare them with a group of volunteers matched for age and gender (Ryan $e t$ al, 2004). Baseline levels of cortisol and AVP were indistinguishable between patients and controls, although patients had higher ACTH levels. Patients with schizophrenia had a higher mean AUC of ACTH $(26.3$ (s.d.=6.2) nmol/l $v .13 .9$ $($ s.d. $=3.0) \mathrm{nmol} / \mathrm{l})$ and cortisol $(279.4$ $($ s.d. $=26.0) \mathrm{nmol} / \mathrm{l} \quad v .213 .1 \quad$ (s.d.=18.4) $\mathrm{nmol} / \mathrm{l}$ ) but had a lower mean AUC of AVP $\quad(0.87 \quad$ (s.d. $=0.24) \mathrm{pmol} / \mathrm{l} \quad v . \quad 1.42$ (s.d. $=0.34) \mathrm{pmol} / \mathrm{l}$ ) than controls. A positive correlation between plasma levels of AVP and cortisol, and higher levels of plasma ACTH during the test period, indicate that the pituitary-adrenal axis was more sensitive to vasopressin-mediated stimulation in our patients with schizophrenia. This may be due first to the fact that vasopressin can directly stimulate the release of cortisol from the adrenal cortex (Guillon $e t$ al, 1995), and second, to the fact that glucocorticoid-induced inhibition of AVP gene transcription may be overcome, thereby allowing this hypothalamic neuropeptide to stimulate the pituitary-adrenal axis (Rivier \& Vale, 1983; Kovacs \& Sawchenko, 1996; Aguilera \& RabadanDiehl, 2000; Aguilera et al, 2000), leading to a relative hypercortisolaemia with all its consequent effects.

\section{DISCUSSION}

Conclusions are difficult to draw, either from the literature at large or even from this short paper. However, there are indications that the illness of schizophrenia is associated with not only an increase in visceral fat distribution but also impaired fasting glucose levels independently of medication, possibly due to a dysfunctional HPA axis. To clarify matters we need prospective studies examining the effects of medication on drug-naïve patients with first-episode schizophrenia. Second, all patients with schizophrenia require regular physical examinations and need to have their blood glucose and lipids measured on a regular basis by either their primary care doctor or (if necessary) their psychiatrist.

\section{CLINICAL IMPLICATIONS}

Drug-naïve patients with first-episode schizophrenia may have important metabolic disturbances, including central obesity and impaired fasting glucose levels.

- Clinicians should be aware of the cardiovascular complications associated with such metabolic disturbances and ensure that their patients have regular contact with their general practitioner - or indeed a diabetologist.

- Appropriate clinicians should not only monitor plasma glucose levels but also check for signs of central obesity by measuring waist-hip ratios at diagnosis and also at regular intervals thereafter.

\section{LIMITATIONS}

The definitions of diabetes and schizophrenia used by earlier researchers would not conform to the rigour of modern standards, and therefore the observations and rates quoted may not be wholly accurate.

- The numbers of patients used in the studies described were small and it may be difficult to extrapolate these findings to larger populations. Larger prospective studies need to be performed.

- A literature search over such a broad area cannot be regarded as fully comprehensive. Some papers were not translated from their original language.

JOGIN H. THAKORE, PhD, MRCPI, MRCPsych, Senior Lecturer in Psychiatry, Royal College of Surgeons in Ireland; Neuroscience Centre, St Vincent's Hospital, Richmond Road, Fairview, Dublin 3, Ireland. Tel: +353 I 884 2400; fax: +353 I 884 2450; E-mail: jthakore@rcsi.ie

\section{REFERENCES}

Aguilera, G. \& Rabadan-Diehl, C. (2000) Vasopressinergic regulation of the hypothalamicpituitary-adrenal axis: implications for stress adaptation. Regulatory Peptides, 96, 23-29.

Aguilera, G., Lightman, S. L. \& Ma, X.-M. (2000) Transcriptional and post-transcriptional regulation of corticotrophin releasing hormone and vasopressin expression by stress and glucocorticoids. In Stress: Neural, Endocrine and Molecular Studies (eds R. McCarty G. Aguilera \& R. Kvetnansky), pp. 182-191. Amsterdam: Harwood

Alberti, K. G. M. M. (1996) The clinical implications of impaired glucose tolerance. Diabetic Medicine, I3, 927-937.

Allison, D. B., Fontaine, K. R., Heo, M., et al (1999a) The distribution of body mass index among individuals with and without schizophrenia. Journal of Clinical Psychiatry, 60, 215-220.

Allison, D. B., Mentore, J. L. \& Moonseong, H. (1999b) Antipsychotic-induced weight gain: a comprehensive research synthesis. American fournal of Psychiatry, 156, 1686-1696.

Altamura, A. C., Guercetti, G. \& Percudani, M. (1989) Dexamethasone suppression test in positive and negative schizophrenia. Psychiatry Research, 30, 69-75.
American Diabetes Association (1997) Report of the expert committee on the diagnosis and classification of diabetes mellitus. Diabetes Care, 20, 1183-1197.

Axelrod, J. \& Reisine, T. D. (1984) Stress hormones: their interaction and regulation. Science, 224, 452-459.

Braceland, F. J., Meduna, L. J. \& Vaichulis, J. (1945) Delayed action of insulin in schizophrenia. American Journal of Psychiatry, 102, 108-110.

Breier, A. \& Buchanan, R. W. (1992) The effects of metabolic stress on plasma progesterone in healthy volunteers and schizophrenic patients. Life Sciences, 5I I527-I534.

Brown, S. (1997) Excess mortality of schizophrenia: a meta-analysis. British Journal of Psychiatry, I7I, 502-508.

Brown, S., Barraclough, B. \& Inskip, H. (2000) Causes of the excess mortality of schizophrenia. British Journal of Psychiatry, 177, 212-217.

Brugha, T. S., Wing, J. K. \& Smith, B. L. (1989) Physical health of the long-term mentally ill in the community: is there unmet need? British Journal of Psychiatry, 155, 777-781.

Colditz, G. A., Manson, J. E., Stampfer, M. J., et al (1992) Diet and risk of clinical diabetes in women. American Journal of Clinical Nutrition, 55, 1018-1023.

Condren, R. M. \& Thakore, J. H. (200I) Cushing's disease and melancholia. Stress, 4, 91-119. 
Coryell, W. \& Tsuang, D. (1992) Hypothalamicpituitary-adrenal axis hyperactivity and psychosis recovery during an 8 year follow-up. American journal of Psychiatry, 149, 1033-10399.

Cotter, D. \& Pariante, C. M. (2002) Stress and the progression of the developmental hypothesis of schizophrenia. British Journal of Psychiatry, I8I, 363-365.

Dewan, M. J., Pandurangi, A. K., Boucher, M. L., et al (1982) Abnormal dexamethasone suppression test results in chronic schizophrenic patients. American Journal of Psychiatry, 139, 150I-1503.

Elman, L., Adler, C. M., Malhotra, A. K., et al (1998) Effect of acute metabolic stress on pituitary-adrenal axis activation in patients with schizophrenia. American journal of Psychiatry, 155, 979-981.

Enzi, G., Gasparo, M., Biondetti, P. R., et al (1986) Subcutaneous and visceral fat distribution according to age, sex and overweight, evaluated by computed tomography. American Journal of Clinical Nutrition, 44, 739-746.

Freeman, H. (1946) Resistance to insulin in mentally disturbed soldiers. Archives in Neurology and Psychiatry, 56, 74-78.

Gil-Ad, I., Dickerman, Z., Amdusky, S., et al (1986) Diurnal rhythm of plasma beta endorphin, cortisol and growth hormone in schizophrenics as compared to control subjects. Psychopharmacology, 88, 496-499.

Goldbourt, U. \& Neufeld, H. N. (1988) Genetic aspects of arteriosclerosis. Arteriosclerosis, 6, 357-377.

Gourdy, P., Ruidavets, L. B., Ferieres, J., et al (200I) The Monica Study 1995-1997. Prevalence of type 2 diabetes and impaired fasting glucose in the middle aged population of three French regions - the MONICA study 1995-1997. Diabetes and Metabolism, 27, 347-358.

Guillon, G., Trueba, M., Joubert, D., et al (1995) Vasopressin stimulates steroid hormone secretion in human adrenal glands: comparison with angiotensin-II effect. Endocrinology, 136, 1285-1295.

Halbreich, U., Zumoff, B., Kream, J., et al (1982) The mean 1300-1600 h plasma cortisol concentration as a diagnostic test for hypercortisolaemia. Journal of Clinical Endocrinology and Metabolism, 54, 1262-1264.

Heiskanen, T., Niskanen, L., Lyytikainen, R., et a (2003) Metabolic syndrome in patients with schizophrenia. Journal of Clinical Psychiatry, 64, 575-579.

Hellewell, J. S. (1999) Treatment-resistant schizophrenia: reviewing the options and identifying the way forward. Journal of Clinical Psychiatry 60 (suppl. 23) 14-19.

Hill, J. O., Wyatt, H. R., Reed, G.W., et al (2003) Obesity and the environment: Where do we go from here? Science, 299, 853-855.

Holsboer, F. (1998) The endocrinology of mental disease. In Clinical Endocrinology (ed. A Grossman), pp. 1096-1I16. Oxford: Blackwell.

Inskip, H. M., Harris, C. \& Barraclough, B. (1998) Lifetime risk of suicide for affective disorder, alcoholism and schizophrenia. British Journal of Psychiatry, 172 35-37.

Kaneda, Y., Fujii, A. \& Ohmori, T. (2002) The hypothalamic-pituitary-adrenal axis in chronic schizophrenic patients long-term treated with neuroleptics. Progress in Neuro-psychopharmacology and Biological Psychiatry, 26, 935-938.

Kaneko, M., Yokoyama, F., Hoshino, Y., et al (1992) Hypothalamic - pituitary-adrenal axis function in chronic schizophrenia: association with clinical features. Neuropsychobiology, 25, 1-7.

Kendrick, T. (1996) Cardiovascular and respiratory risk factors and symptoms among general practice patients with long-term mental illness. British Journal of Psychiatry 169, 733-739.

King, H. \& WHO Ad Hoc Reporting Group (1993) Global estimates for prevalence of diabetes mellitus and impaired glucose tolerance in adults. Diabetes Care, 16, 157-177.

Kovacs, K. J. \& Sawchenko, P. E. (1996) Sequence of stress induced alterations in indices of synaptic and transcriptional activation in parvocellular secretory neurons. Journal of Neuroscience, 16, 262-273.

Lammers, C. H., Garcia Boreguero, D., Schmider, J., et al (1995) Combined dexamethasone/corticotropin releasing hormone test in patients with schizophrenia and in normal controls. Biological Psychiatry, 38, 803-807.

Langfeldt, G. (1952) The insulin tolerance test in mental disorders. Acta Psychiatrica Scandinavica, 80 (suppl.), 189-200.

Lieberman, J. A., Phillips, M., Hongbin, G., et a (2003) Atypical and conventional antipsychotic drug in treatment-naïve first episode schizophrenia: a 52 week randomized trial of clozapine vs. chlorpromazine. Neuropsychopharmacology, 28, 995-1003.

Liebzeit, K. A., Markowitz, J. S. \& Caley, C. F. (200I) New onset diabetes and atypical antipsychotics. European Neuropsychopharmacology, II, 25-32.

Lorenz, W. F. (1922) Sugar tolerance in dementia praecox and other mental disorders. Archives of Neurology and Psychiatry, 8, 184-196.

Mukherjee, S., Schnur, D. B. \& Reddy, R. (1989) Family history of type 2 diabetes in schizophrenic patients. Lancet, i, 495

Mukherjee, S., Decina, P., Bocola, V., et al (1996)

Diabetes mellitus in schizophrenic patients. Comprehensive Psychiatry, 37, 68-73.

Muller, O. A. \& von Werder, K. (1989) Diagnostic dilemmas in hypercortisolism: investigation and management. In Neuroendocrine Perspectives (eds E. E. Muller \& R. M. Macleod), vol. 6, p. 293. Berlin: Springer

Ottoson, M., Vikman-Adolfson, K. \& Enerback, $S$. (1994) The effects of cortisol on the regulation of lipoprotein lipase activity in human adipose tissue. Journal of Clinical Endocrinology and Metabolism, 79 $820-825$.

Pedersen, S. B., Jonier, M. \& Richelsen, B. (1994) Characterisation of regional and gender differences in glucocorticoid receptors and lipoprotein lipase activity in human adipose tissue. Journal of Clinical Endocrinology and Metabolism, 78, 1354-1359.

Rao, M., Strebel, B. \& Halaris, A. (1995) Circadian rhythm of vital signs, norepinephrine, epinephrine, thyroid hormones and cortisol in schizophrenia. Psychiatry Research, 57, 21-39.

Reaven, G. (1988) Banting Lecture 1988. Role of insulin resistance in human disease. Diabetologia, 30, 1595-1607.

Rivier, C. \& Vale, W. (1983) Modulation of stressinduced ACTH release by corticotrophin-releasing factor, catecholamines and vasopressin. Nature, $\mathbf{3 0 5}$, 325-327.

Rosmond, R. \& Bjorntorp, P. (2002) The hypothalamic-pituitary-adrenal axis activity as a predictor of cardiovascular disease, type 2 diabetes and stroke. Journal of Internal Medicine, 247, 188-197.
Roy, A., Pickar, D., Doran, A., et al (1986) The corticotrophin-releasing hormone stimulation test in chronic schizophrenia. American Journal of Psychiatry, 143, 1393-1397.

Ryan, M. C. M. \& Thakore, J. H. (2002) Physical consequences of schizophrenia and its treatment: the metabolic syndrome. Life Sciences, 7I, 239-257.

Ryan, M. C. M., Collins, P. \& Thakore, J. H. (2003) Impaired fasting glucose and elevation of cortisol in drug-naïve first-episode schizophrenia. American Journal of Psychiatry, 160, 284-289.

Ryan, M. C. M., Sharifi, N. \& Condren, R. (2004) Evidence of basal pituitary-adrenal overactivity in first episode, drug naïve patients with schizophrenia. Psychoneuroendocrinology, in press.

Salmeron, J., Ascherio, A., Rimm, E. B., et al (1997) Dietary fibre, glycaemic load and the risk of NIDDM in men. Diabetes Care, 20, 545-550.

Salmeron, J., Hu, F. B., Manson, J. E., et al (200I) Dietary fat and risk of type 2 diabetes in women. American Journal of Clinical Nutrition, 13, 1019-1027.

Sernyak, M. J., Leslie, D. L., Alarcon, R. D., et a (2002) Association of diabetes mellitus with use of atypical neuroleptics in the treatment of schizophrenia. American Journal of Psychiatry, 159, 561-566.

Shaten, B. J., Kuller, L., Davey Smith, G., et al (1993) Risk factor for the development of type II diabetes among men enrolled in the usual care group of multiple risk factor intervention trial. Diabetes Care, 16 |33|-1339.

Subramaniam, M., Chong, S. \& Pek, E. (2003) Diabetes mellitus and glucose tolerance in patients with schizophrenia. Canadian Journal of Psychiatry, 48. 345-347.

Tandon, R., Mazzara, C., De Quardo, J., et al (1991) Dexamethasone suppression test in schizophrenia: relationship to symptomatology, ventricular enlargement, and outcome. Biological Psychiatry, 29 953-964.

Taylor, D. M. \& McAskill, R. (2000) Atypical antipsychotics and weight gain - a systematic review. Acta Psychiatrica Scandinavica, 10I, 416-432.

Thakore, J. H., Vlahoos, J. \& Martin, A. (2002) Increased visceral fat distribution in drug-naïve and drug-free patients with schizophrenia. International Journal of Obesity Related Metabolic Disorders, 26, |37-|4|.

Van Cauter, E., Linkowski, P., Kerkhofs, M., et al (1991) Circadian and sleep-related endocrine rhythms in schizophrenia. Archives of General Psychiatry, 48, 348-356.

Wajchenberg, B. L., Bosco, A., Marone, M. M. et al (1995) Estimation of body fat and lean tissue distribution by dual energy $X$-ray absorptiometry and abdominal body fat evaluation by computed tomography in Cushing's disease. Journal of Clinical Endocrinology and Metabolism, 80, 279|-2794.

Whalley, L. J., Christie, J. E., Blackwood, D. H., et al (1989) Disturbed endocrine function in the psychoses. I: Disordered homeostasis or disease process? British Journal of Psychiatry, 155, 455-461.

Wood, D., Backer, G. D., Faergeman, O., et al (1998) Prevention of coronary heart disease in clinical practice: recommendations of the Second Joint Task Force of European and other Societies on coronary prevention. Atherosclerosis, 140, 199-270. 